\title{
Detecting, Counting Objects to Form Color Image Features
}

\author{
Dr. Mohammad S. Khrisat ${ }^{1}$, Prof. Ziad A. Alqadi ${ }^{2}$ \\ Albalqa Applied University ${ }^{1}$, CE, FET, Amman, Jordan ${ }^{1}$ \\ Albalqa Applied University ${ }^{2}$, CE, FET, Amman, Jordan ${ }^{2}$
}

\begin{abstract}
Color image features are very important victor of values. Which is used as an image identifier or primary key which can be used easily in a color image retrieval system, the features victor can be used also as an image signature to compute image classifier in a color image recognition system. In this paper research we will introduce a texture method to create color image features. This method will have based on using crossing number to detect some objects in the image, the detected objects where isolated, ending, connected and crossing points. The idea of the proposed method is to find the count of each objects, these counts will form the image features. The proposed method will be implemented and the experimental results will be analyzed to prove the efficiency, accuracy, and stability of the proposed method.
\end{abstract}

Keywords: Features, crossing number, isolated point, ending point, connected point, crossing point.

\section{INTRODUCTION}

Digital color images [1], [2], [3] are the most popular data types used by human[23], [24], they are used in various application such image retrieval systems and image recognition system, these systems are used in many industrial and business applications [4], [5], [6].

Digital images can be represented by a 2D matrix (gray image), or 3D matrix (RGB color image) [9], theses matrices can be easily implemented applying various arithmetic and logical operation. In this research paper we will focus on color images because they are used in various important and vital applications [7], [8].

Digital color image usually has a high resolution which leads to dealing with a huge size consisting of megabytes, thus the process of image matching will require long time and a poor efficient retrieval or recognition system, table 1 shows various images with different sizes, these images will be used later in the proposed method implementation [10], [11], [12].

Table 1: Example of used images

\begin{tabular}{|c|cc|c|}
\hline Image number & Resolution(pixel) & Size(byte) \\
\hline 1 & $151 \quad 333$ & 150849 \\
\hline 2 & $152 \quad 171$ & 77976 \\
\hline 3 & $360 \quad 480$ & 518400 \\
\hline 4 & $1071 \quad 1600$ & 5140800 \\
\hline 5 & $981 \quad 1470$ & 4326210 \\
\hline 6 & 165247 & 122265 \\
\hline 7 & 360480 & 518400 \\
\hline 8 & $183 \quad 275$ & 150975 \\
\hline 9 & $183 \quad 275$ & 150975 \\
\hline 10 & $201 \quad 251$ & 151353 \\
\hline 11 & 600 & 1050 & 1890000 \\
\hline 12 & 1144 & 1783 & 6119256 \\
\hline
\end{tabular}

To overcome the previous mentioned problem, we can use the image features to deal with the image. Image features can be defined as a set of values (victor); these values must satisfy the following:

- $\quad$ THE FEATURES VALUES MUST BE NUMERIC TO SIMPLIFY THE PROCESS OF IMPLEMENTATION.

- $\quad$ THE NUMBER OF ELEMENTS MUST BE SMALL TO MINIMIZE THE FEATURES DATABASE SIZE.

- $\quad$ FOR EACH IMAGE THE FEATURES MUST BE UNIQUE AND CAPABLE TO BE USED AS A PRIMARY KEY OR SIGNATURE.

- $\quad$ THE FEATURES MUST DEPEND ON THE IMAGE TEXTURE.

- $\quad$ THE FEATURES MUST BE STABLE FOR EACH IMAGE, AND DOES NOT CHANGE FROM ONE RUN TO ANOTHER. 


\section{International Journal of Advanced Research in Computer and Communication Engineering}

Vol. 9, Issue 11, November 2020

DOI 10.17148/IJARCCE.2020.91112

Features extraction time must be minimal and small.

\section{RELATED WORKS}

Many methods were proposed to create color image features [13], [14], many of these methods are based on local binary pattern (LBP) method, these methods provide high efficiency by requiring a small extraction time [15], [16], but these methods are sensitive to image rotation, any image rotation will generate new different features, broking the features stability condition [17].

Some methods were based on using statistical parameters to generate the features; these methods require bigger time of features extraction. Some other method such as k_mean clustering method to group the image intensity values into groups or clusters, and the centre of the defined number of clusters can be used as features [18], [19]. These methods are flexible by giving the user the ability of forming the features (clusters centres or within clusters sums or the counts of data items in each cluster).Clustering based method are not efficient because they require a long time of features extraction.

Other used methods are based on wavelet packet tree (WPT) decomposition [20], [21], [22], these methods are efficient, but it is difficult to select the number of decomposition levels required to form a fix number of feature values, because the images sizes are not fixed and change from image to another (see table 1).

\section{III.THE PROPOSED METHOD}

The proposed method detects some objects in the color image and counts them, these counts are to used as an image features, these objects are four: isolated, ending, connecting and crossing points as shown in figure 1.

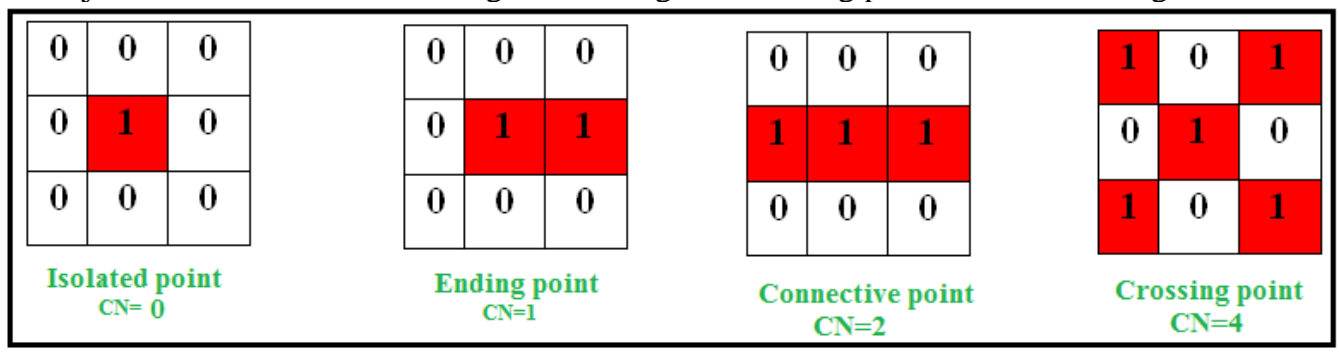

Figure 1: Objects to be detected

The proposed method can be implemented applying the following steps:

1) Color image preprocessing:

This step must be implemented using the following sequence of operations:

- $\quad$ Select the color image.

- $\quad$ Convert the color image to gray image.

- $\quad$ Convert the gray image to binary image.

- $\quad$ Apply image thinning using morphological thinning.

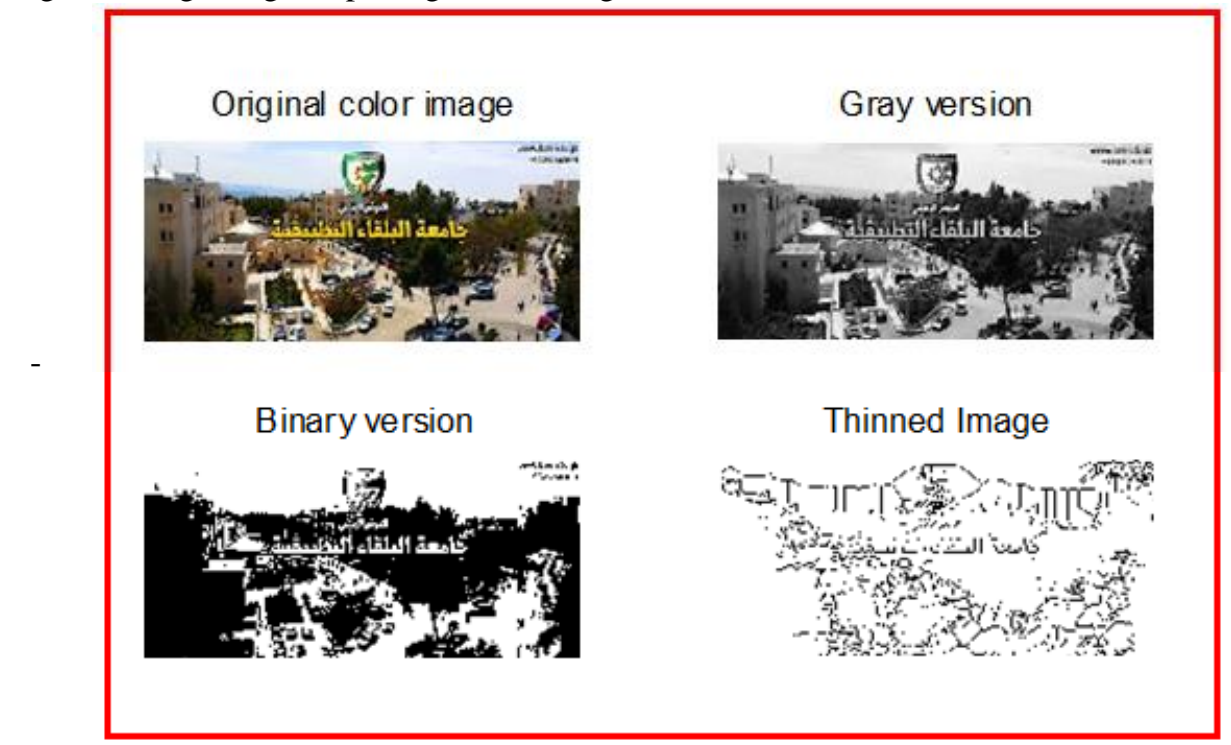

Figure 2: Step 1 outputs (image 1) 


\section{International Journal of Advanced Research in Computer and Communication Engineering}

Vol. 9, Issue 11, November 2020

DOI 10.17148/IJARCCE.2020.91112

2) For each pixel in the binary image, detect the object based on the 8-neighbor value (eq. 1) and referening to the calculated value of the crossing number as shown in figure 3, for the detected object add one the object count.

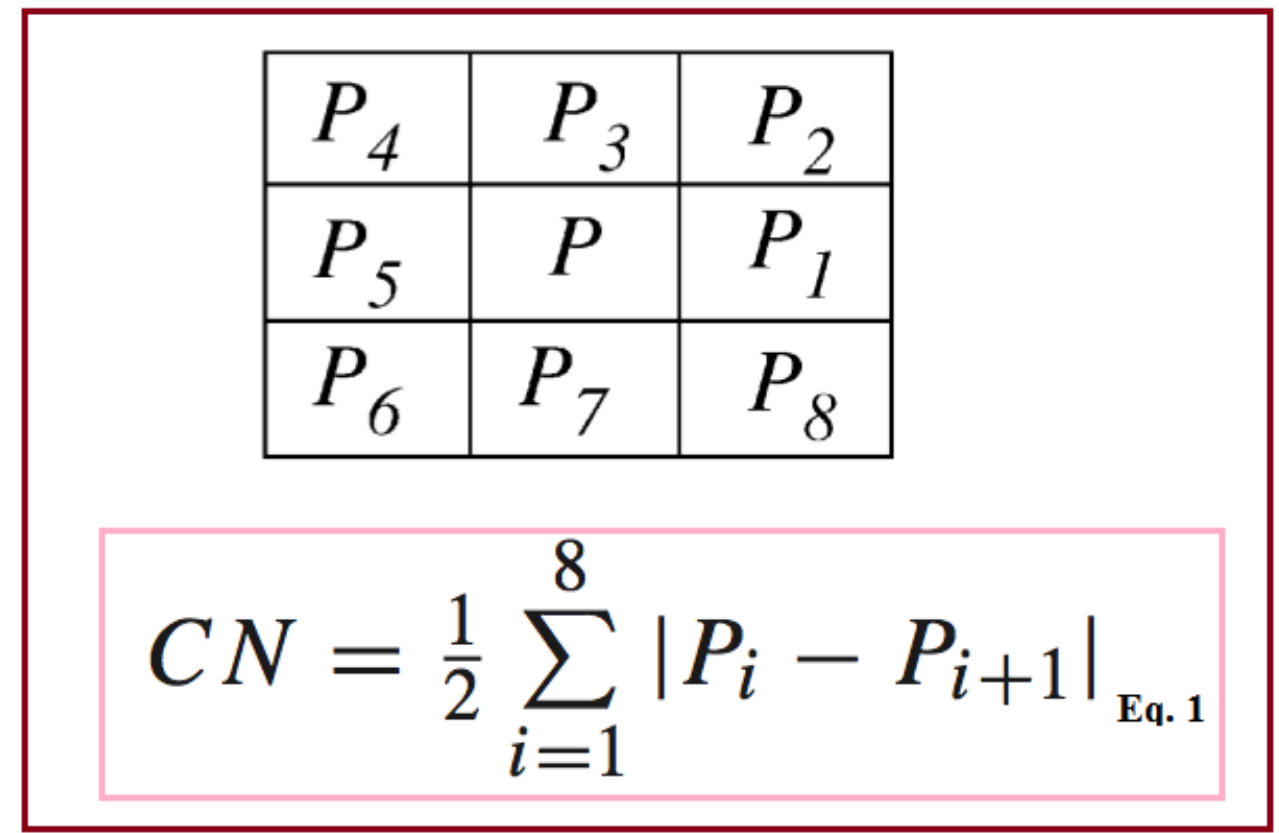

Figure 3: Crossing number calculation

\section{IV.IMPLEMENTATION AND EXPERIMENTAL RESULTS}

Images shown in table 1 were proccessed using matlab, figure 4 shows image 2 versions, while figure 5 shows the connective points to this image:

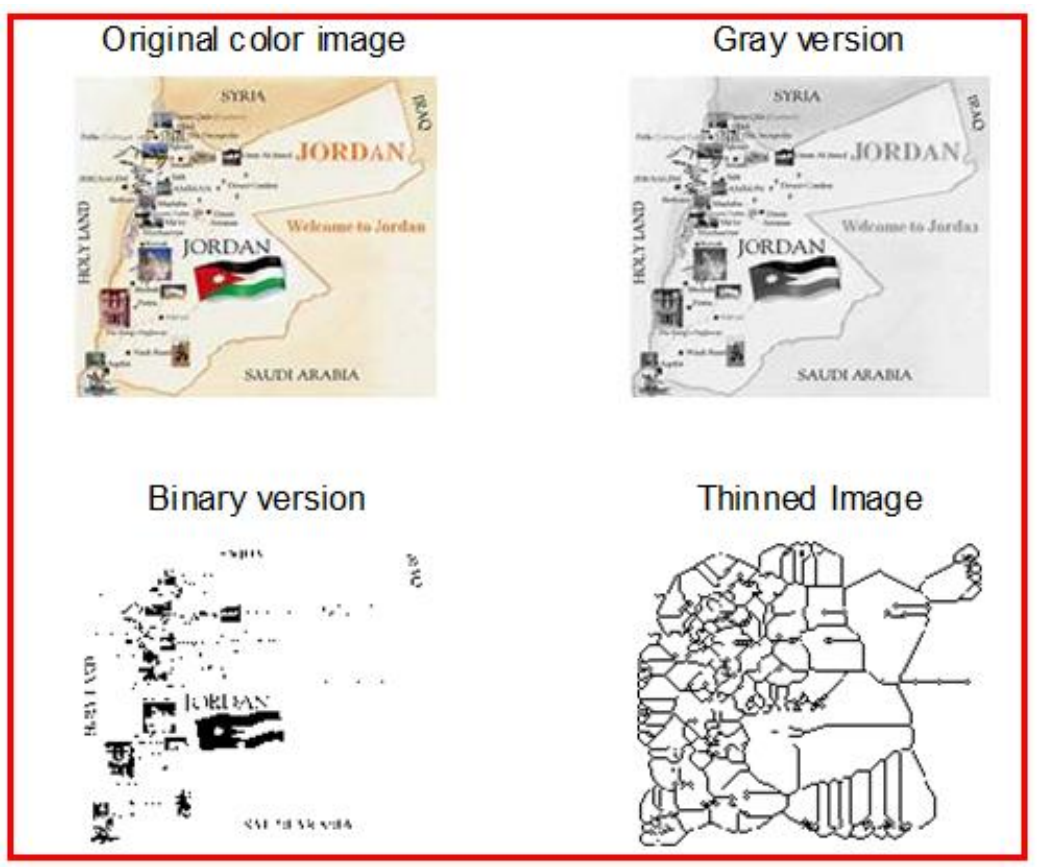

Figure 4: Image 2 versions 


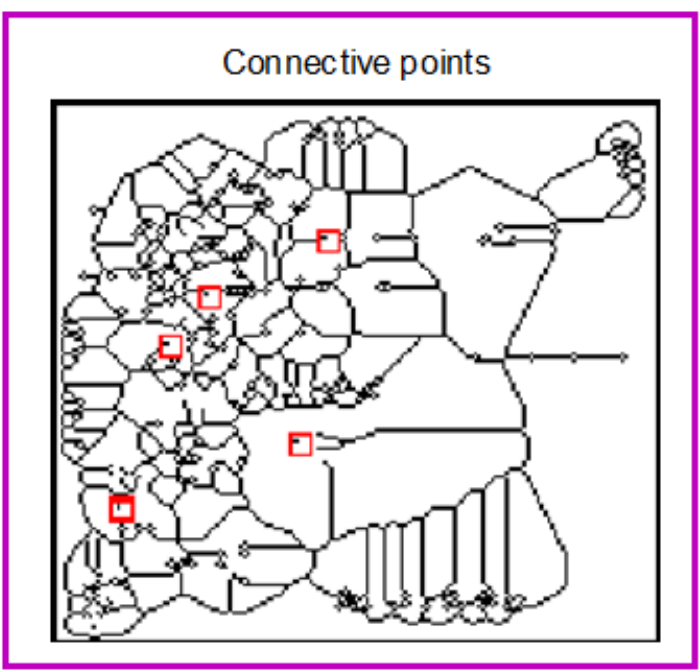

Figure 5: Connecting points for image 2

Each of the detected points has an $\mathrm{x}$ and $\mathrm{y}$ coordinates, figure 6 shows the coordonates for the connected points of image 2 .

\begin{tabular}{rr}
\multicolumn{1}{|r}{} & $\mathbf{Y}$ \\
117 & 21 \\
118 & 21 \\
71 & 35 \\
57 & 46 \\
99 & 72 \\
41 & 80
\end{tabular}

Figure 6: Connecting points coordinates (image 2)

Figure 7 shows the ending points for image 1, while figure 8 shows the coordinates of these points:

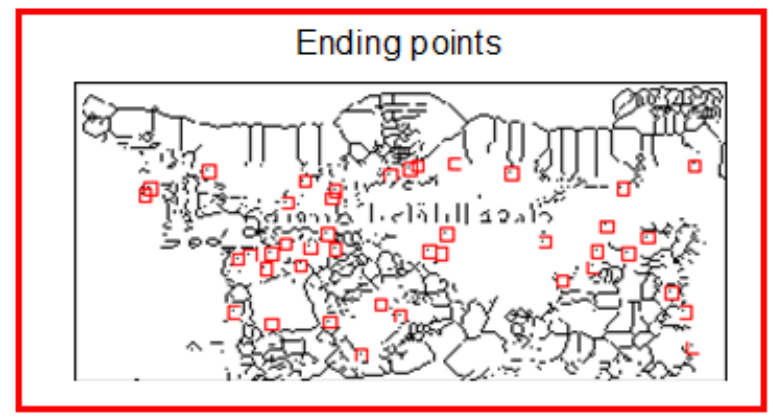

Figure 7: Ending points (image 2) 
DOI 10.17148/IJARCCE.2020.91112

\begin{tabular}{|c|c|c|c|c|c|}
\hline 59 & 38 & \multirow{21}{*}{$\begin{array}{l}\text { Coordinates of } \\
\text { points from } \\
1 \text { to } 21\end{array}$} & 49 & 164 & \multirow{21}{*}{$\begin{array}{l}\text { Coordinates of } \\
\text { points from } \\
22 \text { to } 42\end{array}$} \\
\hline 56 & 41 & & 121 & 169 & \\
\hline 47 & 71 & & 46 & 174 & \\
\hline 119 & 84 & & 44 & 178 & \\
\hline 92 & 86 & & 88 & 184 & \\
\hline 90 & 92 & & 89 & 190 & \\
\hline 97 & 100 & & 79 & 193 & \\
\hline 89 & 103 & & 43 & 197 & \\
\hline 125 & 103 & & 48 & 226 & \\
\hline 84 & 110 & & 83 & 243 & \\
\hline 63 & 111 & & 103 & 252 & \\
\hline 95 & 118 & & 96 & 268 & \\
\hline 52 & 120 & & 88 & 270 & \\
\hline 86 & 123 & & 75 & 275 & \\
\hline 79 & 132 & & 56 & 283 & \\
\hline 124 & 133 & & 89 & 286 & \\
\hline 61 & 134 & & 81 & 296 & \\
\hline 57 & 136 & & 109 & 308 & \\
\hline 87 & 136 & & 119 & 315 & \\
\hline 141 & 149 & & 137 & 319 & \\
\hline 115 & 159 & & 44 & 320 & \\
\hline
\end{tabular}

Figure 8: Ending points coordinates (image 1)

The 4 selected objects were detetected for each image, and the count of each object was finded, table 2 shows the obtained experimental result.

From table 2 we can see that the proposed method satisfies the requirements of good method of features extraction by providing the following advantages:

It requires an average extraction time of 0.8583 seconds, thus we can cosider it as an efficient method comparing with other mentioned existing methods of features eaxtraction.

- $\quad$ The features for each are unique, thus we can use these features as an imgae primary key or signature.

- The features victor contains small number of elements, which leads to minimizing the size of the features database.

- $\quad$ The features are stable and do not change fron run to run.

- $\quad$ The features remain without change even if we rotate the image.

Table 2: Objects counts (features) for each image

\begin{tabular}{|c|c|c|c|c|c|}
\hline \multirow[t]{2}{*}{ Image } & \multicolumn{4}{|c|}{ Points counts } & \multirow{2}{*}{$\begin{array}{c}\text { Extraction } \\
\text { time(seconds) }\end{array}$} \\
\hline & Isolated & Ending & Connecting & Crossing & \\
\hline 1 & 48003 & 42 & 131 & 314 & 0.083249 \\
\hline 2 & 24726 & 0 & 6 & 115 & 0.045659 \\
\hline 3 & 165611 & 89 & 423 & 878 & 0.277279 \\
\hline 4 & 1628423 & 980 & 3698 & 7561 & 2.777550 \\
\hline 5 & 1390886 & 1050 & 3691 & 5310 & 2.227815 \\
\hline 6 & 39503 & 18 & 78 & 188 & 0.070951 \\
\hline 7 & 166018 & 119 & 366 & 770 & 0.271745 \\
\hline 8 & 50403 & 13 & 41 & 150 & 0.072149 \\
\hline 9 & 49272 & 68 & 127 & 254 & 0.077176 \\
\hline 10 & 48273 & 54 & 150 & 349 & 0.083784 \\
\hline 11 & 612392 & 71 & 549 & 1815 & 0.945822 \\
\hline 12 & 1935214 & 728 & 1748 & 5057 & 3.366517 \\
\hline \multicolumn{5}{|c|}{ Average } & 0.8583 \\
\hline
\end{tabular}




\title{
International Journal of Advanced Research in Computer and Communication Engineering
}

\author{
Vol. 9, Issue 11, November 2020
}

\section{DOI 10.17148/IJARCCE.2020.91112}

\section{Conclusion}

A method of color image features extraction was proposed, implemented and tested. The obtained experimental results showed that based on objects counts in any image with any size we can create a small features victor. This victor is unique for each image and can be easily used in an image retrieval or recognition system. Base on the obtained average extraction time we can consider the proposed method as efficient method of image features extraction.

\section{REFERENCES}

[1] Majed O Al-Dwairi, Ziad A Alqadi, Amjad A Abujazar, Rushdi Abu Zneit, Optimized true-color image processing, World Applied Sciences Journal, vol. 8, issue 10, pp. 1175-1182, 2010.

[2] Jamil Al Azzeh, Hussein Alhatamleh, Ziad A Alqadi, Mohammad Khalil Abuzalata, Creating a Color Map to be used to Convert a Gray Image to Color Image, International Journal of Computer Applications, vol. 153, issue 2, pp. 31-34, 2016.

[3] Jamil Al-Azzeh, Ziad Alqadi, Mohammed Abuzalata, Performance Analysis of Artificial Neural Networks used for Color Image Recognition and Retrieving, international Journal of Computer Science and Mobile computing, vol. 8, issue 2, pp. 20-33, 2019.

[4] Dr. Amjad Hindi, Dr. Majed Omar Dwairi, Prof. Ziad Alqadi, Analysis of Procedures used to build an Optimal Fingerprint Recognition System, International Journal of Computer Science and Mobile Computing, vol. 9, issue 2, pp. 21 - 37, 2020.

[5]Ziad A AlQadi Amjad Y Hindi, O Dwairi Majed, PROCEDURES FOR SPEECH RECOGNITION USING LPC AND ANN, International Journal of Engineering Technology Research \& Management, vol. 4, issue 2, pp. 48-55, 2020.

[6] Aws AlQaisi, Mokhled AlTarawneh, Ziad A. Alqadi, Ahmad A. Sharadqah, Analysis of Color Image Features Extraction using Texture Methods, TELKOMNIKA, vol. 17, issue 3, pp. 1220-1225, 2019.

[7]Ahmad Sharadqh Naseem Asad, Ismail Shayeb, Qazem Jaber, Belal Ayyoub, Ziad Alqadi, Creating a Stable and Fixed Features Array for Digital Color Image, IJCSMC, vol. 8, issue 8, pp. 50-56, 2019.

[8] Ziad Alqadi, Dr. Mohammad S. Khrisat, Dr. Amjad Hindi, Dr. Majed Omar Dwairi, VALUABLE WAVELET PACKET INFORMATION TO ANALYZE COLOR IMAGES FEATURES, International Journal of Current Advanced Research, vol. 9, issue 2, pp. 2319,2020.

[9] Majed O. Al-Dwairi, Amjad Y. Hendi, Mohamed S. Soliman, Ziad A.A. Alqadi, A new method for voice signal features creation, International Journal of Electrical and Computer Engineering (IJECE), vol. 9, issue 5, pp. 4092-4098, 2019.

[10]Ziad AlQadi, M Elsayyed Hussein, Window Averaging Method to Create a Feature Victor for RGB Color Image, International Journal of Computer Science and Mobile Computing, vol. 6, issue 2, pp. 60-66, 2017.

[11] Bilal Zahran Belal Ayyoub, Jihad Nader, Ziad Al-Qadi, Suggested Method to Create Color Image Features Victor, Journal of Engineering and Applied Sciences, vol. 14, issue 1, pp. 2203-2207, 2019.

[12]Majed O. Al-Dwairi, Amjad Y. Hendi, Mohamed S. Soliman, Ziad A.A. Alqadi, A new method for voice signal features creation, International Journal of Electrical and Computer Engineering (IJECE), vol. 9, issue 5, pp. 4092-4098, 2019.

[13]Ayman Al-Rawashdeh, Ziad Al-Qadi, Using wave equation to extract digital signal features, Engineering, Technology \& Applied Science Research, vol. 8, issue 4, pp. 1356-1359, 2018.

[14]Ahmad Sharadqh Naseem Asad, Ismail Shayeb, Qazem Jaber, Belal Ayyoub, Ziad Alqadi, Creating a Stable and Fixed Features Array for Digital Color Image, IJCSMC, vol. 8, issue 8, pp. 50-56, 2019.

[15]ZIAD ALQADI, A MODIFIED LBP METHOD TO EXTRACT FEATURES FROM COLOR IMAGES, Journal of Theoretical and Applied Information Technology, vol. 96, issue 10, pp. 3014-3024,2018.

[16]Aws Al-Qaisi, Saleh A Khawatreh, Ahmad A Sharadqah, Ziad A Alqadi, Wave File Features Extraction Using Reduced LBP, International Journal of Electrical and Computer Engineering, vol. 8, issue 5, pp. 2780-2787, 2018.

[17]Jihad Nader Ismail Shayeb, Ziad Alqadi, Jihad Nader, Analysis of digital voice features extraction methods, International Journal of Educational Research and Development, vol. 1, issue 4, pp. 49-55, 2019.

[18]Ahmad Sharadqh Jamil Al-Azzeh, Rashad Rasras, Ziad Alqadi , Belal Ayyoub, Adaptation of matlab K-means clustering function to create Color Image Features, International Journal of Research in Advanced Engineering and Technology, vol. 5, issue 2, pp. 10-18, 2019.

[19] Yousf Eltous Ziad A. AlQadi, Ghazi M. Qaryouti, Mohammad Abuzalata, ANALYSIS OF DIGITAL SIGNAL FEATURES EXTRACTION BASED ON KMEANS CLUSTERING, International Journal of Engineering Technology Research \& Management, vol. 4, issue 1, pp. 66-75, 2020.

[20]Amjad Y Hindi, Majed O Dwairi, Ziad A AlQadi, Creating Human Speech Identifier using WPT, International Journal of Computer Science and Mobile Computing, vol. 9, issue 2, pp. 117-123, 2020.

[21]Amjad Hindi, Majed Omar Dwairi, Ziad Alqadi, Analysis of Digital Signals using Wavelet Packet Tree, IJCSMC, vol. 9, issue 2, pp. 96-103, 2020 .

[22] Ziad Alqadi Dr. Mohammad S. Khrisat, Dr. Amjad Hindi, Dr. Majed Omar Dwairi, VALUABLE WAVELET PACKET INFORMATION TO ANALYZE COLOR IMAGES FEATURES, International Journal of Current Advanced Research, vol. 9, issue 2, pp. 2319-6505, 2020.

[23] Dr. Amjad Hindi, Dr. Ghazi M. Qaryouti, Prof. Yousif Eltous, Prof. Mohammad Abuzalata, Prof. Ziad Alqadi, Color Image Compression using Linear Prediction Coding, International Journal of Computer Science and Mobile Computing, vol. 9, issue 2, pp. 13 - $20,2020$.

[24] Ziad Alqadi, Ahmad Sharadqh, Naseem Asad, Ismail Shayeb, Jamil Al-Azzeh, Belal Ayyoub, A highly secure method of secret message encoding, International Journal of Research in Advanced Engineering and Technology, vol. 5, issue 3, pp. 82-87, 2019. 